\title{
Kourosh Mohammadkhani, Raha Resaleh. “An Achaemenid site in south-east Iran. A magnetic survey at Afraz (Bam-Baravat fault), Kerman"
}

\section{Sébastien Gondet}

\section{(2) OpenEdition}

Journals

Édition électronique

URL : http://journals.openedition.org/abstractairanica/49331

DOI : 10.4000/abstractairanica.49331

ISBN : 1961-960X

ISSN : 1961-960X

Éditeur :

CNRS (UMR 7528 Mondes iraniens et indiens), Éditions de l'IFRI

\section{Référence électronique}

Sébastien Gondet, « Kourosh Mohammadkhani, Raha Resaleh. "An Achaemenid site in south-east Iran. A magnetic survey at Afraz (Bam-Baravat fault), Kerman" », Abstracta Iranica [En ligne], Volume 40-41 | 2019, document 48, mis en ligne le 30 octobre 2019, consulté le 18 avril 2021. URL : http:// journals.openedition.org/abstractairanica/49331 ; DOI : https://doi.org/10.4000/abstractairanica. 49331

Ce document a été généré automatiquement le 18 avril 2021.

Tous droits réservés 


\title{
Kourosh Mohammadkhani, Raha Resaleh. "An Achaemenid site in south-east Iran. A magnetic survey at Afraz (Bam-Baravat fault), Kerman"
}

\author{
Sébastien Gondet
}

\section{RÉFÉRENCE}

Kourosh Mohammadkhani, Raha Resaleh. “An Achaemenid site in south-east Iran. A magnetic survey at Afraz (Bam-Baravat fault), Kerman" in B. Jennings, C. Gaffney, T. Sparrow, S. Gaffney (eds.). 12th International Conference of Archaeological Prospection (12th 16th September 2017, The University of Bradford). Oxford: Archaeopress, 2017, p. 159-160.

Il s'agit du résumé étendu tiré des actes d'un colloque rassemblant la communauté internationale des archéologues-géophysiciens. Il traite de données obtenues suite à une prospection géophysique mise en œuvre sur le site d'Afraz situé dans la région de Bam. Afraz est un des sites fondés au cours de la période achéménide, identifiés et étudiés lors de prospections archéologiques récentes effectuées dans la région de Bam (cf. [cr dans AI vol. 37-38-39 (2014-2016) /2018 - R3.2.2/ n 81]). Le plan de plusieurs grandes constructions a été identifié sur les cartes géophysiques, il pourrait s'agir de bâtiments administratifs. Ces pages permettent d'alimenter le dossier, encore lacunaire, de l'occupation achéménide à l'est de l'Iran. 


\section{AUTEURS}

\section{SÉBASTIEN GONDET}

UMR 5133 CNRS-Université de Lyon 